\title{
Sondeo de Casos en Personas Mayores sobre Actividades Cotidianas y Utilización de Tecnologías de la Información y la Comunicación (TIC) en Tiempos de Pandemia
}

\author{
Survey of Cases in Elderly about Daily Activities and Use of Information and Communications \\ Technology (ICT) in Times of Pandemic
}

Aurora Concepción-Breton ${ }^{1}$, Ismael Corrales-Camacho², María Elena Córdoba ${ }^{3}$, María Encarnación AcostaHernández ${ }^{4}$. Osvaldo Isidro Larancuent-Cueto ${ }^{5}$ v Yandra Lliranilza De La Cruz-Morel ${ }^{6}$

\section{() \\ EDICIÓN: @e-CIVTAC}

Recibido: $14 /$ julio/2020

Aceptado: 2/agosto/2020

Publicado: $25 /$ septiembre/2020

'Instituto Tecnológico de Santo Domingo ${ }^{2}$ Universidad Nacional De Costa Rica ${ }^{3}$ Instituto Tecnológico de Santo Domingo ${ }^{4}$ Instituto Tecnológico de Santo Domingo Instituto Tecnológico de Santo Domingo

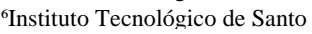

\section{IIIIInstitución}

${ }^{1}$ Instituto Tecnológico de Santo Domingo ${ }^{2}$ Instituto Tecnológico de Santo Domingo ${ }^{3}$ Universidad Nacional De Costa Rica ${ }^{4}$ Instituto Tecnológico de Santo Domingo ${ }^{5}$ Instituto Tecnológico de Santo Domingo ${ }^{6}$ Instituto Tecnológico de Santo Domingo

\section{¿@Correo Eletrónico \\ 1draconcepcionbreton@gmail.com 2ismael.corrales.camacho@una.cr 3macorbu@yahoo.com \\ ${ }^{4}$ maria.acosta@intec.edu.do \\ 5osvaldo.larancuent@intec.edu.do 6yandra_delacruz@hotmail.com \\ D ORCID \\ ${ }^{1}$ https://orcid.org/0000-0002-1873-880X ${ }^{2}$ https://orcid.org/0000-0002-7122-0460 ${ }^{3} \mathrm{https}: / /$ orcid.org/0000-0002-8827-457X ${ }^{4} \mathrm{https}: / /$ orcid.org/0000-0003-2164-262X ${ }^{5}$ https://orcid.org/0000-0002-1108-556X ${ }^{6}$ https://orcid.org/0000-0001-5159-4943}

\section{Citar así: C6APA / IEEE}

Concepción-Breton, A., Corrales-Camacho, I., Córdoba, M., Acosta-Hernández, M. Larancuent-Cueto, O. \& De La Cruz-Morel, Y. (2020). Sondeo de Casos en Personas Mayores sobre Actividades Cotidianas y Utilización de Tecnologías de la Información y la Comunicación (TIC) en Tiempos de Pandemia. Revista Tecnológica-Educativa Docentes 2.0, $9(2)$, $132-150$ https://doi.org/10.37843/rted.v9i2.156

A. Concepción-Breton, I. Corrales-Camacho, $\mathrm{M}$. Córdoba, M. Acosta-Hernández, O. LarancuentCueto y Y. De La Cruz-Morel, "Sondeo de Casos en Personas Mayores sobre Actividades Cotidianas y Utilización de Tecnologías de la Información y la Comunicación (TIC) en Tiempos de Pandemia", RTED, vol. 9, n. ${ }^{\circ}$ 2, pp. 132-150, sep. 2020

\section{Resumen}

República Dominicana, Costa Rica y Argentina fueron el escenario para este sondeo realizado por un equipo interdisciplinario que cuenta con investigadores en los tres países mencionados, quienes se interesaron por conocer algunas de las condiciones que viven las personas mayores (PM) tras el distanciamiento social por la COVID-19 impuesto a partir del 19 marzo 2020. El objetivo fue auscultar a partir de la pandemia si las PM mantienen una vida activa y cuál es el nivel de utilización de las TIC para establecer relaciones, actividades de aprendizaje, recreación y estado emocional. La metodología consistió en recolección de datos utilizando la herramienta de gestión de formularios de Google Forms y para la presentación se utilizó la herramienta R Studio versión 1.3.959, para equipos Apple. La información sobre aprendizaje y estado emocional se complementó con registro anecdótico de asistentes al Programa de Atención Integral de la Persona Adulta Mayor (PAIPAM) de la Universidad Nacional de Costa Rica. Los resultados arrojaron que las PM de esta muestra se mantienen activas realizando tareas del hogar, y utilizan TIC para comunicarse con familia y amigos, aprender nuevos conocimientos y recreación. La pandemia impactó emocionalmente a más de la mitad de la población estudiada, por lo que garantizar las condiciones que faciliten las relaciones vinculares y nuevos aprendizajes en esta época, resulta indispensable. Se concluye así la importancia que las TIC tienen para las PM y la necesidad de crear espacios de capacitación tecnológica que refuercen relaciones intergeneracionales e interpersonales y políticas públicas que lo posibiliten.

Palabras clave: Sondeo, personas mayores, actividades cotidianas, utilización de TIC.

\section{Abstract}

Dominican Republic, Costa Rica and Argentina were the background for this survey carried out by an interdisciplinary team that includes researchers in the three countries mentioned, who were interested in learning about some of the conditions experienced by elderly after social distancing due to COVID-19 imposed since March 19th, 2020. The objective was to find out from the pandemic if the old people maintain an active life and what is the level of use of the ICT to establish relationships, learning activities, recreation, and emotional state. The methodology consisted of data collection using the Google Forms management tool and for the presentation the R Studio version 1.3.959 tool was used, this in case of Apple computers. The information on learning and emotional state was supplemented with an anecdotal record of those attending the Comprehensive Care Program for the Elderly (PAIPAM) of the National University of Costa Rica. The results showed that the elderly of this sample remain active doing household chores, and they use ICT to communicate with family and friends, to learn new knowledge and recreation. The pandemic emotionally impacted more than half of the studied population, so guaranteeing the conditions that facilitate bonding relationships and new learning at this time is essential. This concludes the importance that ICTs have for old people and the need to creating technological training spaces that reinforce intergenerational and interpersonal relationships and public policies that make it possible.

Keywords: Probe, elderly, daily activities, use of ICT. 
Sondeo de Casos en Personas Mayores sobre Actividades Cotidianas y Utilización de Tecnologías de la Información y la Comunicación (TIC) en Tiempos de Pandemia.

\section{Introducción}

La inquietud por conocer si las personas mayores (PM) podrían tener una vida activa aún en tiempos de pandemia, así como el interés por saber si utilizaban la tecnología para estar en contacto con sus familiares y amigos, motivaron este sondeo, con mayor razón por saber que las PM fueron declaradas como las más vulnerables a la COVID-19. Además, las PM necesitan la relación con los demás aún más que en otras etapas de la vida, y en este confinamiento están aisladas, incluso en ocasiones, solas.

Las PM obtienen beneficios relacionados con su bienestar en general cuando comparten la vida con otras personas. Cabe señalar que no siempre esas personas son familiares, aunque en muchos casos ocupan el primer lugar por el rol fundamental que juegan en la consolidación de vínculos afectivos y refuerzo de la autoestima y seguridad. Sin embargo, en ocasiones son los amigos, vecinos y mascotas los que cubren esas necesidades emocionales proporcionando ganancia en la esfera psicológica, emocional y física en el devenir de quienes llegan a la edad avanzada con o sin dolencias físicas.

Resultados de numerosos estudios, como el realizado por Parra-Rizo (2017) concluyen que los componentes que más influyen en la calidad de vida de las personas mayores son la salud, relaciones personales, autonomía funcional y mantenerse activo. Fueron estos factores los que llevaron a cuestionamientos de investigación vinculados con esta etapa donde la pandemia de la COVID-19 impactó a nivel mundial.

La COVID-19 es una enfermedad viral surgida desde finales del año 2019 en la ciudad de Wuhan, República Popular China, según la alerta de brote epidemiológico dicho país y las informaciones en la prensa. Se trata de un tipo de coronavirus denominada COVID-19 de alto contagio y mortalidad, especialmente para personas adultas mayores y personas con problemas de diabetes, respiratorios y cardiacos. Este virus fue declarado una pandemia, el 11 de marzo del año 2020, por la Organización Mundial de la Salud (OMS) que alertó a todos los países a establecer de forma urgente medidas sanitarias de aislamiento social.

El contagio por el virus crecía día a día, pues en la República Dominicana, según reporte del Ministerio de Salud Pública de la República Dominicana (MSP) publicado por Peguero (2020) en,
Diario Libre, los casos al día 28 de abril del año 2020, con corte a las 6:00 de la tarde, recogió 6,416 casos confirmados, 1,165 personas recuperadas, 286 fallecidos. Para la misma fecha el Ministerio de Salud de Argentina (2020) reportó 4,003 casos de infectados, 197 de muertos y 1,162 de recuperados. Mientras que el Ministerio de Salud de Costa Rica (2020) informó de 705 casos confirmados, 306 recuperados y 6 fallecidos. Esta situación más la certeza de la vulnerabilidad de las PM, fueron la inspiración para indagar si ellas mantienen una vida activa y cuál es el nivel de utilización de las Tecnologías de la Información y la Comunicación (TIC) para establecer relaciones, actividades de aprendizaje, recreación y estado emocional.

\section{Relaciones Vinculares en las Personas Mayores}

En las personas mayores resultan indispensables las relaciones para su bienestar personal, siendo el vínculo afectivo la emoción que se tiene al sentir el goce de experimentar la cercanía con otras personas enlazadas por compartir actividades, formas de pensar y otras acciones que resultan estimulantes, vínculo afectivo que también puede darse con mascotas.

Ryff (1989 y 1990) plantea que, en el caso de las personas mayores dominicanas, el bienestar psicológico presenta cinco factores dentro de los cuales está la formación de relaciones positivas con otros y es una de las condiciones ideales finales del individuo para un pleno rendimiento. Algunas dimensiones del bienestar psicológico exhiben evidentes efectos de la edad y otras se mantienen estables. Una de las que permanece relativamente estable es la concerniente a las relaciones positivas con los otros (Citado en Molina \&_Meléndez, 2006).

Parte de lo que indica el señor Andrés Urrutia, quien es el director del Centro de Promoción del Adulto Mayor de Córdoba (CEPRAM) es que las relaciones interpersonales benefician significativamente el conservar la salud física, así como mental de las personas adultas mayores. El afecto y la emoción que se comparten con amigos, vecinos, conocidos, etc. produce sobre todo hormonas que alivian y previenen situaciones propias del estrés, y generan bienestar de carácter psíquico y social (Muñiz, 2018).

Aunado a lo anterior y para ampliar mejor la explicación sobre las relaciones interpersonales, sucede que: 
Sondeo de Casos en Personas Mayores sobre Actividades Cotidianas y Utilización de Tecnologías de la Información y la Comunicación (TIC) en Tiempos de Pandemia.
En declaraciones al programa "Entre Nosotros Rebeca" de Canal 10, de Córdoba, Urrutia señala que "por evidencia empírica como por teoría, la amistad es importante" en las distintas etapas de la vida, y "cuando se es mayor ayuda a compensar pérdidas, se empieza a tener importancia para otro, para los pares, y no siempre se da en la familia” (Muñiz, 2018, p. 4).

Según Tello-Rodríguez et ál. (2016) el componente emocional o afectivo de la cotidianidad de las personas mayores, muchas veces despojadas del favor del grupo familiar o limitadas de interacciones sociales positivas, proporciona significados diferentes a la progresiva reducción de diversas funciones cognitivas, biológicas o sensoriales y, con ella, una mayor vulnerabilidad a variados agentes patógenos. Por el contrario, según los estudios consultados, el sentirse útil y necesitadas por los suyos, confiere bienestar a las personas mayores que suelen vivir más y con mayor calidad de vida que quienes no tienen esa contención familiar.

En otro estudio, Arias \& Polizzi (2011) valoran las relaciones vinculares para el bienestar de las personas mayores, y hacen referencia al hecho de que los vínculos de amistad son más benéficos aún que los familiares para una saludable longevidad. Así también en esta investigación se plantea que los amigos pueden influir de manera positiva las conductas de salud tales como dejar de fumar, pueden animar para buscar ayuda médica o pueden afectar de manera positiva sobre la autoestima, la moral y el humor. La compañía, la risa y el apoyo que recibe de y proporciona a sus amigos podrían contribuir a alargar su tiempo de vida. Es aquí donde radica el beneficio que tienen los amigos sobre los familiares. La amistad según este estudio constituye una importante fuente de apoyo social durante la vejez, tanto por la elevada frecuencia en que son incorporados en la misma como por su atributo de elevada intimidad.

Si bien las relaciones amistosas y familiares son valoradas en unos y otros estudios como esenciales, es la combinación de ambas la que proporciona mayores beneficios en el desarrollo y bienestar de las personas mayores. Según Salinas et ál. (2008) el apoyo social es más fuerte cuando los vínculos están compuestos por familiares y amigos. Esta diversidad de vínculos permite satisfacer las necesidades de la persona mayor de modo que cada uno pueda ofrecer su apoyo desde su posición en la red y sus posibilidades (Citado en Arias \& Polizzi, 2011).
En la Colección Estudios en su Serie Personas Mayores, Prieto et ál. (2009) permite que pueda observarse, sin embargo, que no se agota en la familia y las amistades las relaciones vinculares que son fundamentales para el desarrollo pleno de las personas mayores, otro rubro que cobra importancia vital lo constituyen los vecinos. Al pasar más tiempo en el entorno doméstico, los espacios que rodean a este se configuran como escenarios frecuentes de sus actividades cotidianas, donde no necesariamente se dan relaciones de amistad. Sin embargo, el espacio público cobra gran relevancia en la vida y representa la posibilidad de un entramado social nacido de la contigüidad de los que lo componen, entre quienes pueden brindarse apoyo y reconocimiento social. Cobra características particulares el entorno rural donde "el propio hogar puede convertirse en el espacio público donde se desarrollan las relaciones, reafirmándose así la relevancia del espacio doméstico como el espacio por excelencia de la persona mayor" (Prieto et ál., 2009, p.72).

\section{Envejecimiento Activo}

Las relaciones con personas de la familia, amigos, vecinos y otras personas de la misma edad, están estrechamente vinculadas a un envejecimiento activo. Según Sandoval (2018) el hecho de que las personas mayores interactúen con otras de su misma edad confiere beneficios para mantenerse activas mental y físicamente. La mayoría de las personas asocian la adultez tardía con un gradual debilitamiento de las relaciones interpersonales producto de la disolución familiar y la disminución de roles en la comunidad, ocasionando un incremento en la indiferencia del núcleo familiar.

En esta línea de pensamiento Sandoval (2018) explica que las relaciones interpersonales se convierten en el principal factor protector y de curación, por un lado, brindan la posibilidad de apoyo en necesidades básicas, sino también como la contención emocional y garantía de ayuda en todo momento. Las personas mayores que cuentan con una relación de amistad estrecha tienen más oportunidades de una adultez tardía y feliz.

Cabe señalar que una unión familiar satisfactoria colabora para un envejecimiento activo. De igual modo los encuentros intergeneracionales donde el rol de la persona mayor es respetado, cobra gran valor para la autoestima y bienestar, 
Sondeo de Casos en Personas Mayores sobre Actividades Cotidianas y Utilización de Tecnologías de la Información y la Comunicación (TIC) en Tiempos de Pandemia. indispensables en un envejecimiento activo. La vida actual en la cual es frecuente que la pareja trabaje fuera de la casa, o que los niños estén siendo criados por uno solo de los progenitores, generalmente la madre, ha dado como resultado que muchas veces los abuelos no puedan disfrutar de una vejez placentera acorde a su edad, debido a que se convierten en cuidadores de sus nietos, excediendo ocasionalmente los límites para una persona mayor que también requiere atención. La relación entre abuelos y nietos tiene la mayor riqueza para las personas mayores por los afectos inigualables que moviliza este vínculo, y por las ventajas de este puente intergeneracional

La OMS (2015) define el envejecimiento activo como el "proceso de optimización de las oportunidades de salud, participación y seguridad que tiene como fin mejorar la calidad de vida de las personas a medida que envejecen" (p. 248). Este envejecimiento activo es multifactorial y está vinculado con varias dimensiones, tanto física, como económica, familiar, social, cultural, entre otras. Por lo que, las actividades físicas como caminar, practicar un deporte, realizar labores del hogar, etc. la lectura, el aprendizaje de nuevos conocimientos como un idioma o un curso de literatura, el desarrollo artístico que frecuentemente se desarrolla desde la edad madura, como pintar o hacer artesanías de reciclaje, van dotando junto con las relaciones vinculares, la plataforma para que sea más probable una vejez feliz, con salud y bienestar.

Según lo indicado por García en la revista ¡Hola!: "es más frecuente que la falta de actividad práctica, la falta de motivación y de confianza, el aislamiento y la depresión, sean causa de la disminución del rendimiento cognitivo que el envejecimiento en sí mismo" (2010, párr. 22). Para prevenir una decadencia funcional, enfermedades, prolongar la vida con buena calidad y promover las relaciones sociales, lo más recomendable es evitar el sedentarismo realizando actividades físicas, el cero consumo de tabaco, llevar una alimentación saludable, consumir alcohol de manera moderada y tener una buena administración de los medicamentos en las personas mayores (García, 2010).

\section{Las TIC y el Aprendizaje en las Personas Mayores}

La aparición del coronavirus humano COVID19 ha marcado un fuerte cambio en todos los ámbitos de la vida humana, desde lo personal hasta lo profesional; por lo que no es de sorprenderse que en el caso de las personas adultas mayores se estén presentando cambios abruptos en sus actividades diarias. Para las personas mayores en el área educativa, que puede abarcar el aprendizaje de técnicas prácticas, la adquisición de nuevos conocimientos teóricos o simplemente capacitaciones y actualizaciones profesionales, está sufriendo severas modificaciones que para muchos ha implicado un reto de grandes proporciones, especialmente para aquellas que nunca habían querido lidiar con algún dispositivo de telecomunicación moderno.

En tal sentido, Mujica (2019) hace referencia a la adaptación del sistema educativo a la realidad tecnológica lo que implica que se modifique la manera en la que se comunican y transmiten los conocimientos debido a los constantes cambios del día a día. También Mujica (2019) señala que surgen nuevos escenarios de aprendizaje distintos al salón de clase tradicional. Estos nuevos espacios complementan los tradicionales y amplían la oferta formativa.

Por lo que la adaptación a las nuevas tecnologías educativas, a través de herramientas virtuales ofrecidas por plataformas digitales que ofrecen programas y aplicaciones que permiten tener acceso a una clase, hace que para la población adulta mayor la idea de asumir el reto sea cada vez más necesario e inclusive presionado, si es que quieren seguir con cierta normalidad dentro de la sociedad, esto en un reciente mundo donde deben seguir siendo estrictos con el distanciamiento social para así reducir los riesgos de contagio masivo que terminen por cobrar la vida de las personas de edad avanzada principalmente.

\section{Internet y la Brecha Digital}

Se apreció que una parte de la población global, aproximadamente $59.6 \%$, puede establecer vínculos a distancia con familiares, amigos y relacionados dados los avances de las TIC. Almirón (2002) expuso lo siguiente: "por el camino hemos empezado a digitalizar el contenido del mundo, lo que significa que pronto podremos acceder a todo el conocimiento acumulado por la humanidad a través de cualquier nodo conectado a la Red planetaria en que se ha convertido Internet" (Citado en López, 2007, p. 5). 
Sondeo de Casos en Personas Mayores sobre Actividades Cotidianas y Utilización de Tecnologías de la Información y la Comunicación (TIC) en Tiempos de Pandemia.

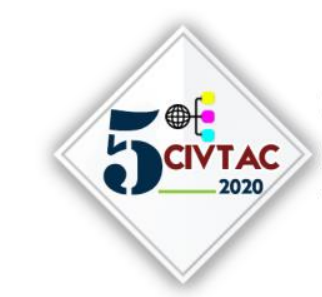

CONGRESO INTERNACIONAL VIRTUAL SOBRE LAS TECNOLOGÍAS DEL APRENDIZAJE Y DEL CONOCIMIENTO

\section{Tabla 1}

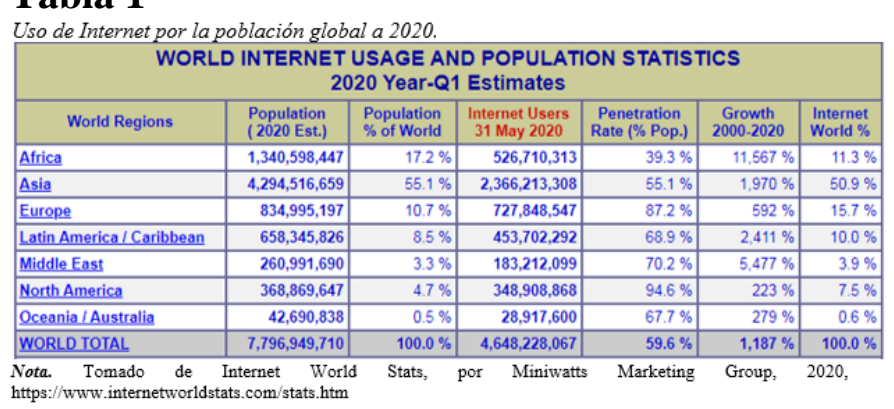

Esta proporción muestra que no todos acceden. En la Tabla 1, se observa que los niveles de acceso o penetración en el uso de Internet en las regiones más desarrolladas como EE. UU. y Europa Occidental oscilan entre el $87.2 \%-94.6 \%$ de la población. Por el contrario, África tiene los peores niveles (39.3\%); incluso América Latina (68.9\%), a pesar de que se acerca a mejores niveles de acceso.

Factores como el despliegue de infraestructuras de acceso a redes para comunidades rurales, suburbanas; así como los altos costos de los equipos, la contratación de los servicios, impuestos excesivos; son barreras que impiden el acceso asequible a Internet, un fenómeno denominado brecha digital, es decir, otro elemento de distancia para alcanzar el desarrollo por los países menos avanzados para permitir que su población pueda acceder a la información, el conocimiento, la productividad e innovación en general.

También hace referencia a los distintos grupos sociales teniendo en cuenta alfabetización además de la capacidad tecnológica (Sevilla, 2015). Cada vez mayores dispositivos electrónicos como las computadoras personales, los dispositivos móviles como laptops, tabletas y celulares; tienen mayor capacidad de acceder a Internet ya sea a través del cableado al hogar (Internet fijo), o de redes de datos inalámbricos (redes celulares, WIFI, entre otros).

\section{La Brecha Digital en Población de Personas Adultas Mayores}

En la brecha digital, no solo influye el acceso asequible a Internet y las TIC, sino también el desarrollo de capacidades para navegar, acceder a información, el entretenimiento, aprendizaje, interacción social, el consumo de servicios disponibles; e incluso la producción de contenidos (Selwyn, 2003). Por otro lado, la barrera generacional es otro elemento influyente en el desarrollo de capacidades para superar la brecha
En la Figura 1 se observan las diferencias de edad en el uso de las TIC, en la que los adultos mayores, son el grupo etario con mayores dificultades para acceder a las mismas, como fue mencionado al inicio de esta sección. En efecto, el problema reside en que hoy en día viven juntos varias generaciones de adultos mayores con diferencias en el aprendizaje y acceso, para los niños no es inconveniente, nacen con la tecnología, aprenden diversidad de idiomas, por esto es importante globalizar las TIC y sobre todo enseñar, como pueden ser útiles para su bienestar, desde el contacto con familiares (Cardozo, 2017).

\section{Figura 1}

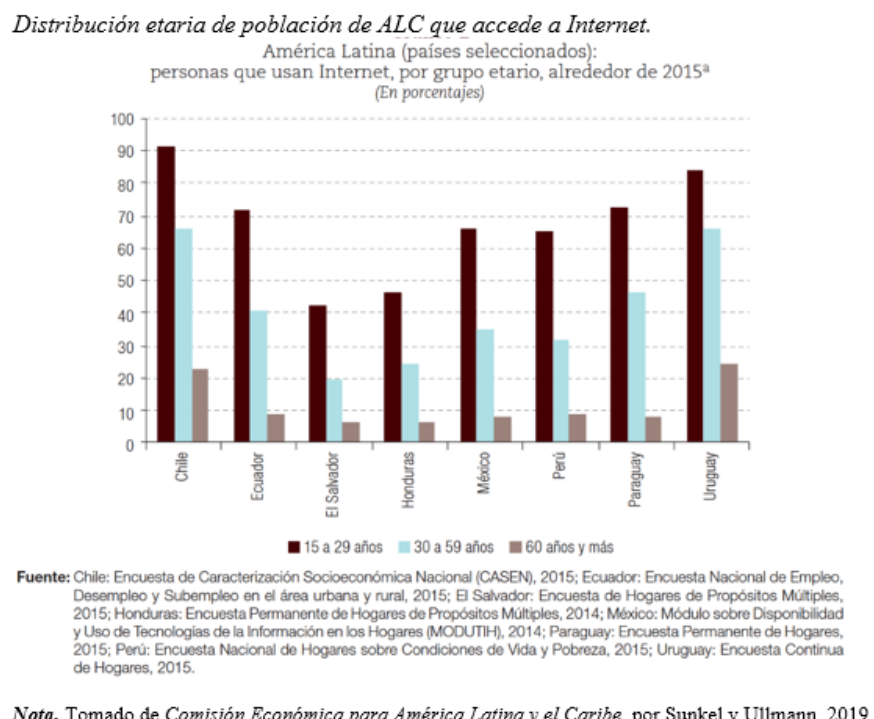

Otro elemento para tener en cuenta es el lugar de acceso a Internet, lo cual influye en la reducción de las barreras identificadas de la brecha generacional. En la Tabla 2, se presentan los casos de países de Centro y Sur América por grupo etario observándose que, en el caso de adultos mayores, el acceso desde el hogar es el de mayor peso porcentual, oscilando entre $89.0 \%$ (Ecuador) y $67.4 \%$ (Honduras). La tabla incluye otros lugares como el lugar de trabajo, la escuela o lugares públicos. 
Sondeo de Casos en Personas Mayores sobre Actividades Cotidianas y Utilización de Tecnologías de la Información y la Comunicación (TIC) en Tiempos de Pandemia.

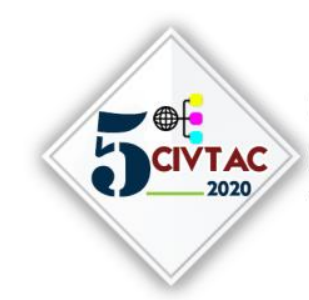

CONGRESO INTERNACIONAL VIRTUAL SOBRE LAS TECNOLOGÍAS DEL APRENDIZAJE Y DEL CONOCIMIENTO
Tabla 2

Lugar de acceso a Internet por grupo etario. América Latina (paises seleccionados): uso de Internet, por lugar de acceso y grupo etario, alrededor de $2015^{\mathrm{a}}$ (En porcentajes)

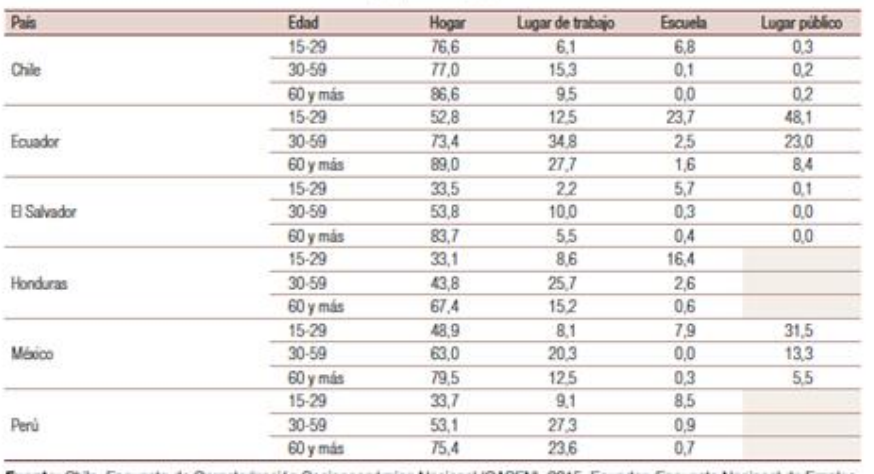

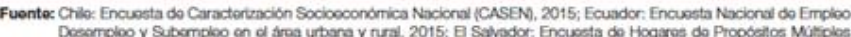

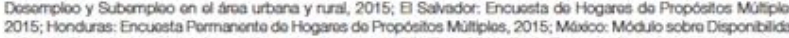

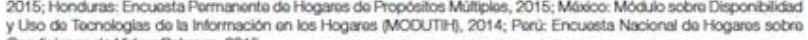
- Las encuestas so noelizaron on 2015, 2015.

Nota. Tomado de Comisión Económica para América Latina y el Caribe, por Sunkel y Ullmann, 2019.

En seguimiento a lo anterior, y lo planteado por Selwyn (2003) la figura 2 presenta evidencias sobre las actividades más frecuentes al acceder a Internet en personas mayores. En el mismo se observa que, aunque predomina el uso de internet para acceder a la información, se presentan casos como Ecuador, Paraguay, El Salvador donde predomina el uso como herramienta de comunicación. Otras actividades que se identifican son: acceso a información, comunicación, entretenimiento, compras en línea, transacciones bancarias, educación y tareas administrativas. Nótese cómo en Chile, Perú, Uruguay el acceso a Internet facilita la realización de mayores actividades que en otros países de la región.

\section{Figura 2}

\section{Actividades en Internet de personas mayores}

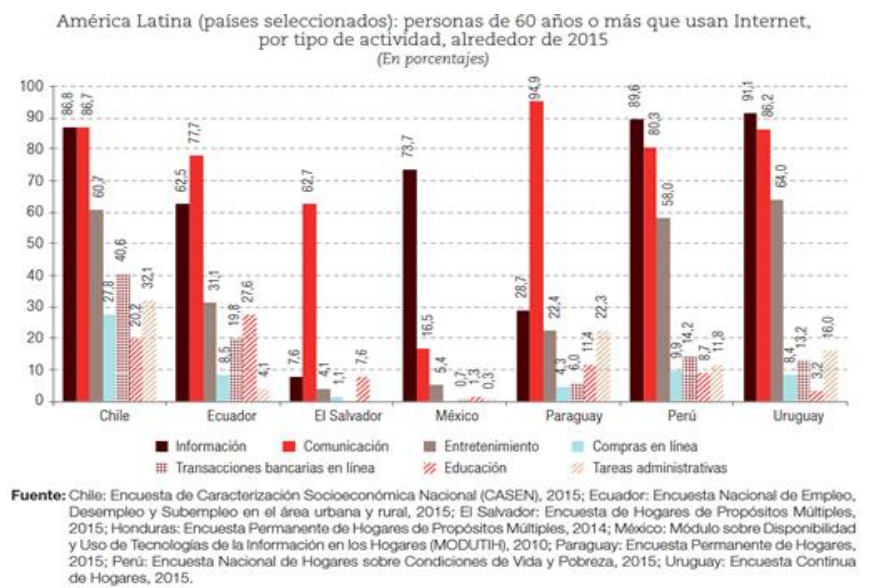

Nota. Tomado de Comisión Económica para América Latina y el Caribe, por Sunkel y Ullmann, 2019.
Respecto a las actividades anteriormente identificadas, Selwyn (2003) identificó factores influyentes para su realización, tales como: discursos de deficiencia material (afectado por factores socioeconómicos), cognitiva (educación), tecnología (motivación o fobia), rechazo ideológico (actitud ante la vida) y teoría de difusión (obsolescencia o sesgo de información sobre la actualidad).

A pesar de estos factores influyentes, las TIC y en especial Internet, ofrecen herramientas que cuando son descubiertas y adoptadas por los adultos mayores, mejoran el bienestar de los adultos mayores, tales como: a) visión deteriorada, tales como; contraste en la visión de plano y fondo, texto puede aumentarse de tamaño y ser leído por persona con discapacidad visual leve, texto con estilo en vez de imágenes para transmitir información, texto que no generen destello. Persona con reducción de destreza o motor fino; posibilidad de aumentar área seleccionable con objetivo, posibilidad de usar el teclado en lugar del ratón. Los de pérdida auditiva se benefician con transcripciones y subtítulos para el contenido de audio, contraste entre los colores de la información de audio, y ruido de fondo (Cardozo, 2017).

\section{Metodología}

El sondeo de casos realizado en personas mayores sobre actividades cotidianas y utilización las TIC en tiempos de pandemia, es de tipo exploratorio, con enfoque mixto y diseño no experimental transversal, se construyó de manera tal que la recolección de datos se llevó a cabo de manera virtual en respuesta al cuestionario de elaboración propia utilizando la herramienta de gestión de formularios de Google Forms y para la presentación se utilizó la herramienta $\mathrm{R}$ Studio versión regin 1.3.959, para equipos Apple. Si bien estos datos recibieron un tratamiento cuantitativo, con intención de dar mayor profundidad a los aspectos de aprendizaje y estado emocional, se levantó un registro anecdótico con análisis del discurso.

\section{Participantes}

La muestra se compuso de 82 personas mayores distribuidas entre 56 en Santo Domingo en República Dominicana, 15 de Heredia de Costa Rica y 11 de la provincia de Córdoba en Argentina. Debido a la cuarentena, como criterio de inclusión se consideró exclusivamente que fueran mayores de 60 
Sondeo de Casos en Personas Mayores sobre Actividades Cotidianas y Utilización de Tecnologías de la Información y la Comunicación (TIC) en Tiempos de Pandemia. años, que aceptaron responder las preguntas o llenar ellos directamente el formulario.

Debido al confinamiento vigente a la fecha de levantar los datos, de abril a junio 2020, la muestra se escogió por conveniencia, de manera que el equipo de investigadores vía WhatsApp, teléfono o correo electrónico envió a contactos conocidos directa o indirectamente que cubrieran los requisitos de inclusión solicitados. En el caso de los participantes de Costa Rica, los que aceptaron ser parte del estudio, participan del PAIPAM.

\section{Instrumento de Recolección de Datos}

Para evaluar si la persona estaba dentro del grupo de lo que se denominan personas mayores activas, se decidió incluir algunas preguntas descriptivas de actividades realizadas durante el día, el interés se centró en detectar si desarrollaban ciertas actividades o mantenían un estado sedentario, no en profundizar en niveles de actividad.

Para la selección de las preguntas y tópicos considerados en la construcción del instrumento, se hizo una amplia revisión bibliográfica y en reuniones constantes usando la plataforma de jitsi, el equipo fue eligiendo las categorías que se incluirían y posteriormente con cuáles preguntas se abordaría cada una de estas categorías y subcategorías.

Quedó así construido un instrumento que abordó datos sociodemográficos, de actividades y de uso de las TIC, con cinco categorías y cada una de ellas con subcategorías de manera que se pudieran cubrir las inquietudes que dieron lugar a este sondeo, el cual fue instrumentado utilizando la herramienta de gestión de formularios de Google Forms y aplicada a personas mayores residentes en Santo Domingo, Costa Rica y Argentina. Ver Apéndice.

En algunos casos se realizaron las preguntas por teléfono o video llamada y el investigador llenó las respuestas, esto ocurrió en siete casos debido a que las personas mostraron interés en participar, pero solicitaron ayuda para el llenado. Antes de la aplicación definitiva, se hizo una prueba piloto con 10 casos a fin de comprobar que el instrumento era claro y las personas mayores podían llenarlo sin dificultad. En dos de estos casos dijeron que les resultó muy claro, pero algo largo ya que les tomó casi 20 minutos llenarlo. El resto expresó que no tuvo dificultad alguna.

Para recolectar datos sobre aprendizaje además de los recogidos en el instrumento mencionado, se trabajó un registro anecdótico con los participantes de Costa Rica, de donde además se obtuvo información respecto a estado de ánimo en épocas del confinamiento.

\section{Procedimiento}

Para este sondeo de casos se utilizó un diseño transversal con enfoque mixto. Se contactaron personas mayores de zonas urbanas y rurales, de ambos sexos mayores de 60 años. Se contactaba a la persona por teléfono, WhatsApp o correo electrónico y se explicaba el motivo del estudio, el anonimato de sus respuestas y se consultaba si podía colaborar con sus respuestas.

En ningún caso se negaron directamente a responder, sin embargo, en 12 casos, manifestaron asentimiento y luego no enviaron el instrumento. Al consultarles si habían tenido algún inconveniente o algo no se entendía, manifestaban que no habían tenido tiempo. En estos casos se ofrecía ayuda para llenarlo y cuatro accedieron a hacerlo así, el resto dijo que lo enviaría, pero no lo hizo.

La duración de llenado fue en promedio de 20 minutos, garantizando el anonimato y aclarando la utilización de los resultados del estudio para fines académicos, y de conocimiento de la situación por funcionarios y público en general. Se recibieron 82 encuestas, a las cuales se dio tratamiento para limpiar, normalizar y asegurar que reunían los requisitos exigidos.

Debido a las limitaciones de Google Forms en la presentación de datos y gráficos legibles, se utilizó la herramienta $\mathrm{R}$ Studio versión 1.3.959, para equipos Apple. Esta herramienta facilitó también los procesos de limpieza, tratamiento y tabulación. Para estos fines se descargó el archivo de datos, en formato de texto, y separado por comas (CSV), y posteriormente fueron cargados a la herramienta. No se detectaron pérdidas en el proceso de migración, y al contrario fueron visibles los datos de fecha y hora que no se veían con Google Forms. Las soluciones aplicadas para limpieza y tratamiento incluyeron técnicas estadísticas tales como: moda para campos categóricos y media para campos numéricos.

\section{Resultados}

Algunos resultados serán presentados acompañados de una breve descripción, y cuando 
Sondeo de Casos en Personas Mayores sobre Actividades Cotidianas y Utilización de Tecnologías de la Información y la Comunicación (TIC) en Tiempos de Pandemia.
CONGRESO INTERNACIONAL VIRTUAL SOBRE LAS TECNOLOGÍAS DEL APRENDIZAJE Y DEL CONOCIMIENTO agreguen valor, de ilustraciones tipo pastel, radar o tablas de datos.

\section{Edad y Sexo de los Entrevistados}

El $72 \%$ de los encuestados son mujeres. Cabe señalar que en todos los casos las mujeres accedían a responder, aunque solicitaban tiempo para hacerlo, argumentando limitaciones de tiempo debido a la carga de actividades que se sumó a las cotidianas por las desinfecciones y protocolos de higiene y en algunos casos debido a que tenían que cuidar a los nietos porque los padres se quedaron sin servicios de guardería o sin servicio doméstico que atendía a los niños, y debían salir a trabajar. Los varones a quienes se solicitó sus respuestas no pusieron objeciones. La proporción de edad promedio de los entrevistados fue de 68 años, con la mayor distribución entre $65-70$ (41.9\%); 70-75 (23.1\%); 60-65 (12.9\%). Véase la Figura 3, para mayores detalles.

\section{Figura 3}

Rangos de edad y sexo de los encuestados.

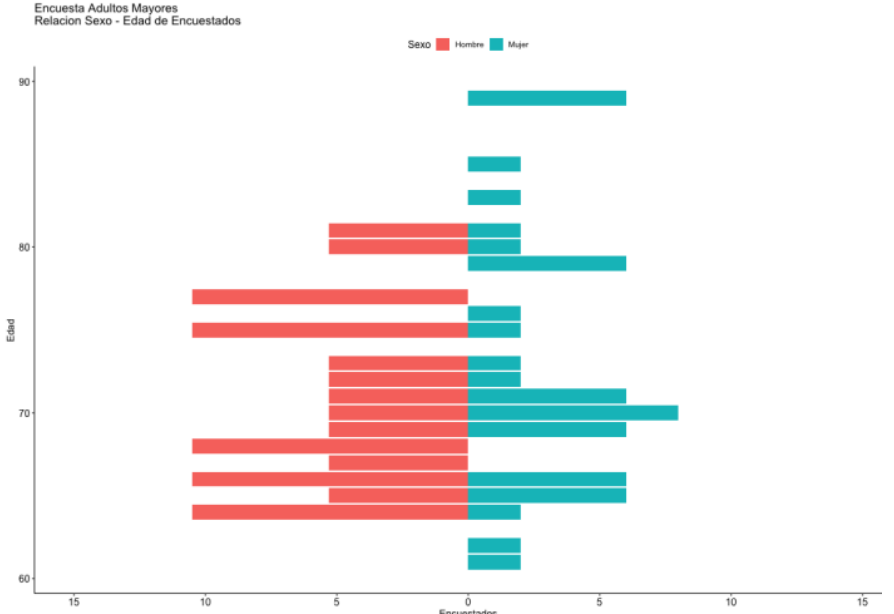

Nota. Relación sexo-edad. Encuesta bienestar mayores, elaboración propia.

\section{Nivel Educativo según Sexo de los Entrevistados}

La estimación del nivel educativo entre los entrevistados fue $57.3 \%$ para niveles de educación terciaria (grado y posgrado); de $14.6 \%$ para nivel técnico-profesional. El $17.1 \%$ corresponde a educación primaria; el $4.9 \%$ a educación secundaria. Véase Figura 4, para mayores detalles. Al cruzar los datos por sexo, se visualiza que los hombres de la muestra han alcanzado mayores niveles de educación terciar.

\section{Figura 4}

Nivel educativo de los entrevistados en función del sexo.

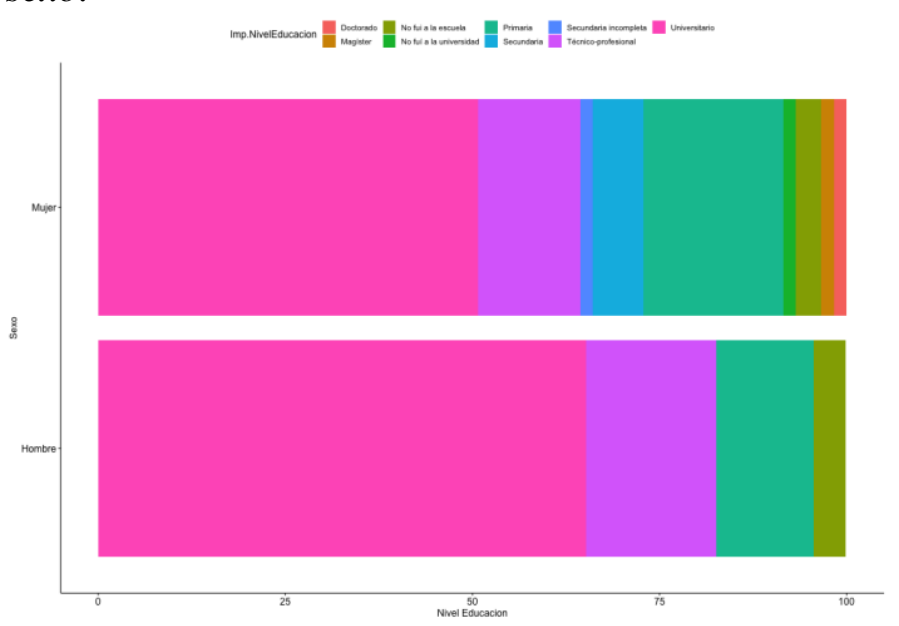

Nota. Relación nivel educativo en función del sexo. Encuesta bienestar adultos mayores, elaboración propia.

\section{Zona de Residencia de los Entrevistados}

La estimación de la zona de residencia de los entrevistados fue $82.9 \%$, para zona urbana; de $17.1 \%$ para zona rural. En las zonas urbanas se tiene mayor acceso a los servicios de comunicación e internet, gracias a la oferta de los diferentes proveedores, lo cual en el caso de las zonas rurales es más precario por razones relacionadas a aspectos socioeconómicos, topografía, e infraestructuras, como las de cableado fijo para acceso al hogar.

\section{Acompañamiento de los Entrevistados}

Consultados con quién viven, las personas entrevistadas respondieron que con familiares en un $76.8 \%$; el $20.7 \%$ indicó que habita solo(a), y el resto con amigos o un servicio. Esta población en un $77 \%$ de los casos está acompañada, lo cual, a efectos de impacto por confinamiento de la pandemia, no aporta tanta información con relación a aislamiento como los que viven solos, que en el caso de esta muestra alcanzan el $21 \%$ solamente.

\section{Estado Laboral de los Entrevistados}

El 53\% de los entrevistados indicó que trabaja, un $30 \%$ que no y un $17 \%$ que está pensionado. La relevancia de esta información permitió identificar qué tan activos se encuentran desde el punto de vista físico y cognitivo; y además clasificar niveles socioeconómicos que propicien el acceso a internet 
Sondeo de Casos en Personas Mayores sobre Actividades Cotidianas y Utilización de Tecnologías de la Información y la Comunicación (TIC) en Tiempos de Pandemia. mediante la contratación de servicios, ya sea desde el hogar o de apropiación tecnológica, utilizando dispositivos electrónicos. Nótese que dentro de las actividades laborales de los que trabajan, estos indicaron las siguientes: 55\% tienen profesión liberal, consultoría o comercio; el $30 \%$ es empleado público o privado; y el $15 \%$, se dedica a la docencia.

\section{Impacto Laboral en los Entrevistados por la Pandemia}

Más de la mitad de los encuestados, (51.2\%) respondió que la pandemia tuvo un impacto en su productividad, ya sea porque se quedó sin posibilidad de continuar con el trabajo que tenía o mermó su ingreso por disminución del trabajo. Esta información es relevante desde el punto de vista de sus capacidades socioeconómicas, lo cual puede ser uno de los factores vinculados a estados de ánimo desfavorables, sin embargo, también está relacionada con los niveles de ocio, ya que esta merma o falta de trabajo, les facilita tiempo para la búsqueda de informaciones y comunicarse, entre otros, que los mantengan activo; e incluso este impacto en su desempeño laboral, puede afectar el acceso a herramientas o equipos informáticos.

\section{Estado de Ánimo en los Entrevistados por la Pandemia}

Se han reclasificado estos estados de ánimo en tres categorías, obteniendo los siguientes resultados: estresados, $71 \%$; bien, $19 \%$; regular, $10 \%$. Es interesante observar que solo un 19 por ciento de las personas entrevistadas indican sentirse bien, si se consideran las características socioeconómicas de esta muestra, este dato abre nuevas líneas de investigación para poblaciones más desprotegidas y para quienes viven en asilos que no fueron objeto de este sondeo. En la Figura 5, se desglosan las más frecuentes sensaciones expresadas en quienes evidenciaron estar estresados: preocupación (14\%), miedo (22\%), incertidumbre (13\%) malhumor $(8 \%)$ y estresados $(14 \%)$.

\section{Figura 5}

Estados anímicos en encuestados estresados por la pandemia.

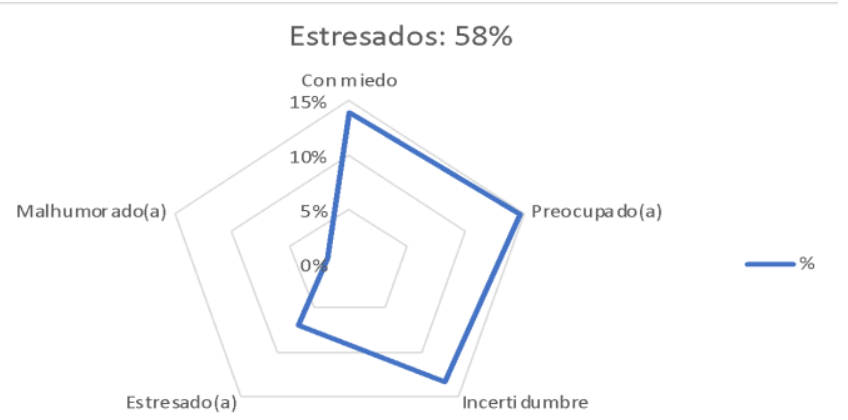

Nota. Desglose de sanciones en pacientes estresados. Encuesta bienestar adultos mayores, elaboración propia.

\section{Actividades más Frecuentes en Horario Matutino}

Basados en las diferentes actividades indicadas se crearon las siguientes categorías, que agrupan el $75 \%$ de las actividades realizadas en horario matutino: Aseo, 25\%; Oficios de la casa, 19\%, Alimentación $16 \%$, Aprendizaje 15\%, entre otras. Véase la Figura 6. En la categoría de aprendizaje (15\%) las actividades se agruparon en: leer libros o buscar información, ver videos instructivos y escribir documentos.

\section{Figura 6}

Actividades matutinas más frecuentes.

Actividades más frecuentes en horario matutino

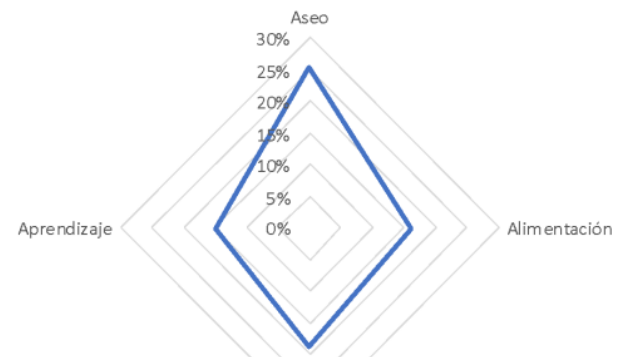

Quehaceres

Nota. Desglose de actividades matutinas más frecuentes Encuesta bienestar adultos mayores, elaboración propia.

\section{Actividades más Frecuentes en Horario Vespertino}

Se reagruparon las actividades realizadas en horario vespertino en las siguientes categorías, representando el $96 \%$ de las actividades, en orden de frecuencia: Entretenimiento, 38\%; Oficios de la casa, 25\%, Aprendizaje, 15\%; Aseo, 9\%; Alimentación 
Sondeo de Casos en Personas Mayores sobre Actividades Cotidianas y Utilización de Tecnologías de la Información y la Comunicación (TIC) en Tiempos de Pandemia.
CONGRESO INTERNACIONAL VIRTUAL SOBRE LAS TECNOLOGÍAS DEL APRENDIZAJE Y DEL CONOCIMIENTO

\section{Figura 7}

Actividades vespertinas más frecuentes.

Actividades más frecuentes en horario vespertino

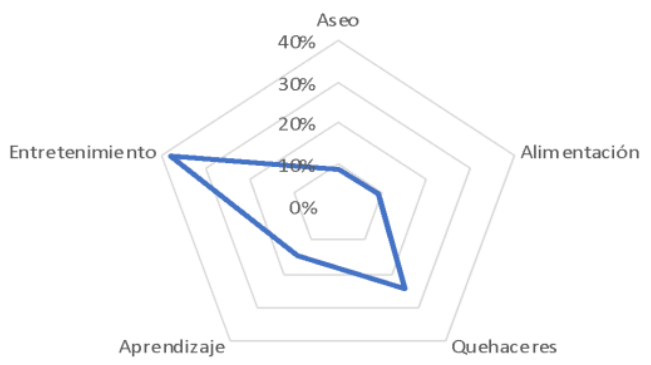

Nota. Desglose de actividades vespertinas más frecuentes. Encuesta Bienestar adultos mayores, elaboración propia.

\section{Actividades más Frecuentes en Horario Nocturno}

Se reagruparon las actividades en las siguientes categorías, representando el $96 \%$ de las actividades, en orden de frecuencia: Entretenimiento, 34\%; Descanso, 23\%, Actividades de fe, 15\%; Alimentación 15\%; Aseo, 9\%. Véase Figura 8. Cabe señalar que en horario nocturno no se mencionaron actividades de oficios en la casa ni las relacionadas con aprendizaje, como leer, aprender idioma o analizar información, que sí fueron mencionadas durante la mañana y la tarde.

\section{Figura 8}

Actividades nocturnas más frecuentes.

Actividades más frecuentes en horario nocturno

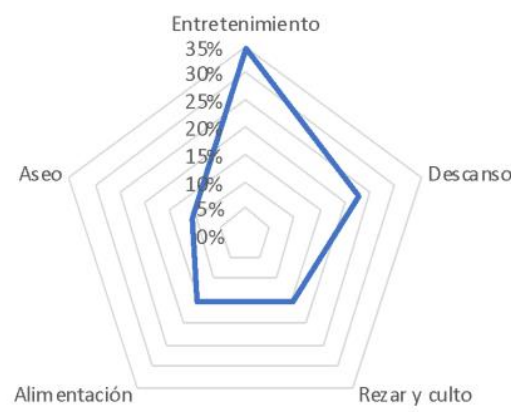

Nota. Desglose de actividades vespertinas más frecuentes. Encuesta Bienestar adultos mayores, elaboración propia.

\section{Interés por Realizar Actividades Permitidas, pero que no ha Podido}

El $89 \%$ de los encuestados expresó que pudieron realizar sus actividades de interés, sin mayores inconvenientes y lo que indicaron como limitante, era el no poder reunirse con su familias y amigos, lo cual está directamente relacionado con la calidad de vida como puedo verse en la revisión teórica, y que se consideró como uno de los elementos indicadores para realizar este sondeo. Esta limitación de no poder reunirse con familiares y amigos no podrá ponderarse hasta que pase un tiempo y se puede considerar hasta dónde afectó en la calidad de vida de las PM.

\section{Discapacidad Física o de Movilidad}

Respecto a discapacidades físicas, el $74 \%$ indicó que no tiene; el $13 \%$ indicó que tiene discapacidades visuales; $7 \%$ auditiva; $5 \%$ de movilidad; y $2 \%$ cognitiva. Como puede comprobarse en la muestra estudiada, no existen mayores dificultades vinculadas con la edad, el que un $74 \%$ se considere sanos, da cuenta de que en esta población no hay representación de PM con discapacidades, lo cual es un alentador pronóstico vinculado con la vejez saludable.

\section{Acceso y Servicios de Internet}

Los encuestados respondieron: $96.3 \%$ tiene acceso a Internet. Asimismo, un $48.8 \%$ indicó que lo paga por sí mismo(a); 32.9\% indicó que su familia; $18.3 \%$ indicó que otras personas no son familiares. Véase Figura 9, para mayores detalles. Dado que la mitad de los encuestados indicó que trabajan, es comprensible que un $49 \%$ diga que ellos mismos asumen en gasto del servicio de internet. Sí es significativo el que casi el total de las personas encuestadas tienen acceso a internet.

\section{Figura 9}

¿Quién paga el internet que consume? ¿QUIÉN PAGA EL INTERNET QUE CONSUME?

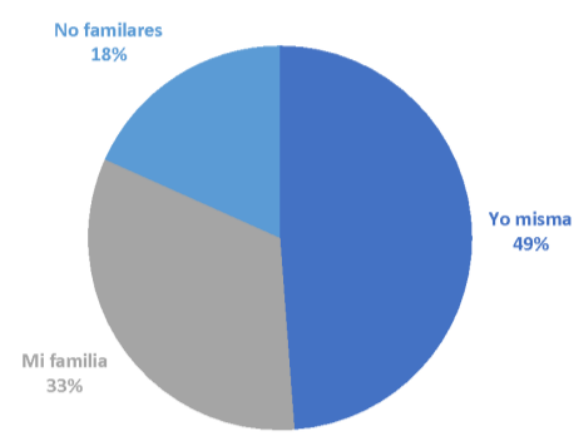

Nota. Desglose de pago de internet. Encuesta Bienestar adultos mayores elaboración propia. 
Sondeo de Casos en Personas Mayores sobre Actividades Cotidianas y Utilización de Tecnologías de la Información y la Comunicación (TIC) en Tiempos de Pandemia.
CONGRESO INTERNACIONAL VIRTUAL SOBRE LAS TECNOLOGÍAS DEL APRENDIZAJE Y DEL CONOCIMIENTO
Actividades Realizadas en el Computador Personal (PC)

Entre las actividades que realizan en el computador personal o de escritorio, el $41 \%$ indicó que lo utiliza para el aprendizaje. Dentro de las tareas agrupadas para estas actividades, citaron: leer información o libros, ver videos instructivos, estudiar y aprender nuevos conocimientos y habilidades, escribir documentos entre otras. Véase detalle en Figura 10. Otras actividades realizadas son: $17.4 \%$ de los entrevistados indicó usa el computador para realizar llamadas; el 11\%, navegar por Internet; el 11\% para uso de redes sociales; y otros (chat, ejercicios, terapia, novelas, reuniones virtuales). Vale decir que el 41 por ciento de los encuestados usan el PC para aprendizajes y un $28 \%$ para comunicarse, en proporción mucho mayor para actividades de aprendizaje que el uso de tableta o celular que los porcentajes son similares para ambas actividades.

\section{Figura 10}

Actividades de aprendizaje realizadas en PC. ACTIVIDADES DE APRENDIZAJE REALIZADA EN LA PC

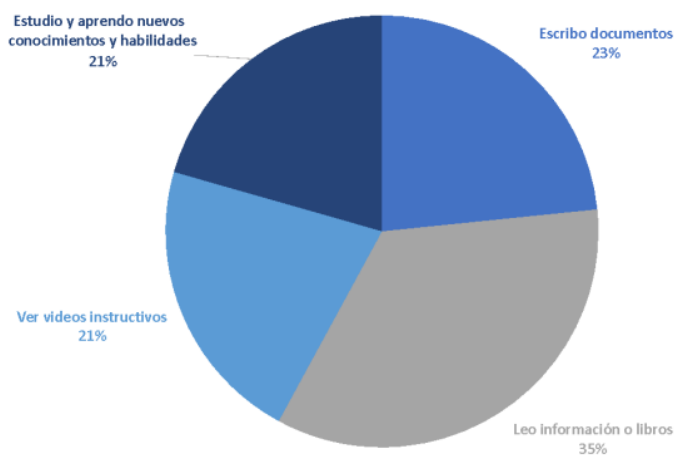

Nota. Desglose de actividades vespertinas más frecuentes. Encuesta Bienestar adultos mayores, elaboración propia.

\section{Tableta o iPad}

El 35\% de quienes indicaron utilizar la tableta, lo hacen para actividades relacionadas al aprendizaje. Dentro de las tareas agrupadas para estas actividades, citaron: leer información o libros, ver videos instructivos, estudiar idiomas y aprender nuevos conocimientos y habilidades, escribir documentos entre otras. Véase Figura 11. En otras actividades realizadas, el $29.3 \%$ utiliza la tableta para hacer llamadas; el 9.8\%, para uso de redes sociales; y otras (chat, culto, terapia) en porcentaje menor. Al igual que ocurre con el celular, casi en igual proporción usan la tableta para aprender y para comunicarse.

\section{Figura 11}

Actividades de aprendizaje realizadas en Tabletas.

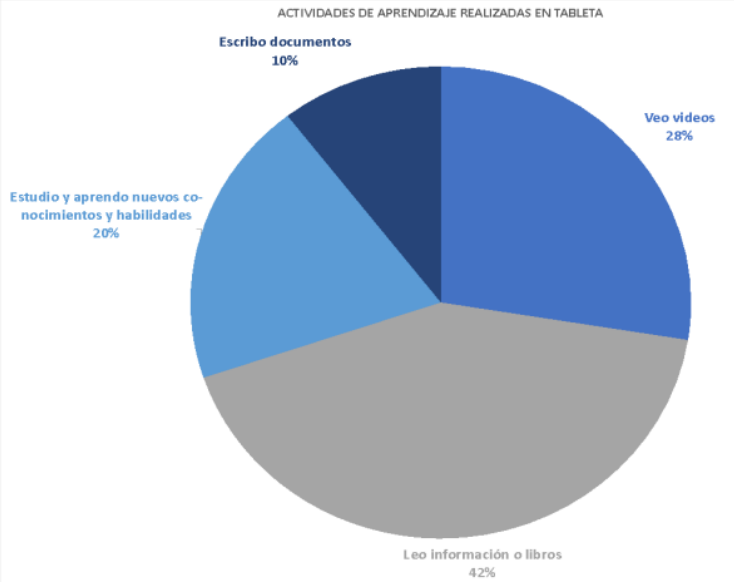

Nota. Desglose de actividades vespertinas más frecuentes. Encuesta Bienestar adultos mayores, elaboración propia.

\section{Tareas Realiza con el Celular Inteligente o Smartphone}

Las actividades relacionadas al aprendizaje con los celulares alcanzaron un $36 \%$. Dentro de las tareas agrupadas para estas actividades, citaron: leer información o libros, ver videos instructivos, estudiar y aprender nuevos conocimientos, entre ellos idiomas y aprender habilidades, escribir documentos entre otras. Véase Figura 12. En otras actividades realizadas, el $17.7 \%$ de los entrevistados indicó que utiliza el celular para hacer llamadas; el 12.4\%, para chatear o texto; $11.3 \%$ para ver vídeos; $11.1 \%$ para navegar por Internet; $8.7 \%$ redes sociales. En resumen, el 36 por ciento lo usan para aprender algo y con un leve aumento, un 39 por ciento, para estar comunicados.

\section{Figura 12}

Actividades de aprendizaje realizadas con celular inteligente.

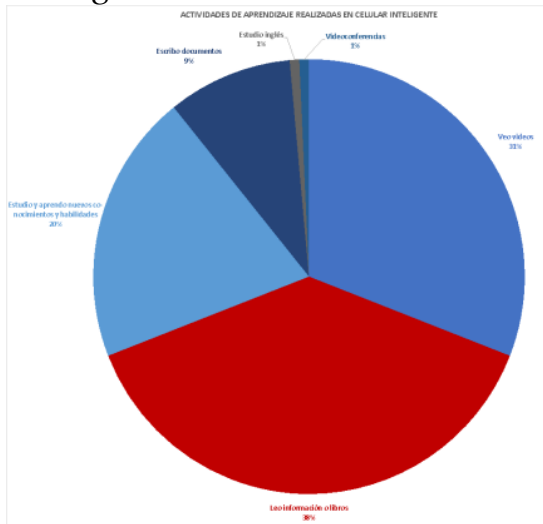

Nota. Desglose de actividades de aprendizaje en celular inteligente, elaboración propia. 
Sondeo de Casos en Personas Mayores sobre Actividades Cotidianas y Utilización de Tecnologías de la Información y la Comunicación (TIC) en Tiempos de Pandemia.
CONGRESO INTERNACIONAL VIRTUAL SOBRE LAS TECNOLOGÍAS DEL APRENDIZAJE Y DEL CONOCIMIENTO
Aplicaciones Informáticas Utilizadas con Mayor Frecuencia

El 17.2\% de los entrevistados indicó que las aplicaciones informáticas más utilizadas son las de chatear o texto; $14.9 \%$ indicó redes sociales; $14.9 \%$ videos, preferido para estudiar y aprender nuevos conocimientos; $12.9 \%$ navegar por Internet; $12.6 \%$ correo electrónico, videoconferencias, $11.3 \%$, periódicos digitales, $10.9 \%$, y otras $5.3 \%$. Véase la Figura 13.

\section{Figura 13}

Aplicaciones informáticas más utilizadas por los entrevistados

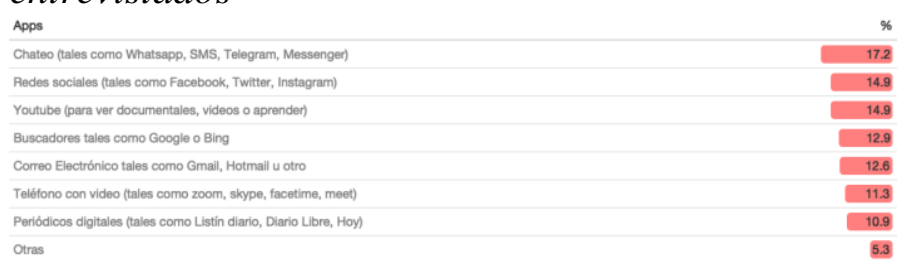

Nota. Desglose de aplicaciones informáticas más utilizadas. Encuesta Bienestar adultos mayores, elaboración propia.

\section{Variación en Uso de las TIC a Causa de la Pandemia}

El $73 \%$ que utiliza TIC, indicó que han tenido un mayor uso; $19 \%$ indicó que mantiene el mismo uso; y $8 \%$ indicó que ha dado un menor uso. Véase Figura 14. Como era de esperarse la mayoría ha dado más uso a la tecnología en época de pandemia, ya que se convirtió en un puente con familiares y amigos, con quienes pudieron estar comunicados gracias a ella, además de actividades laborales que pudieron desarrollar desde la casa y diversos aprendizajes.

\section{Figura 14}

Variación en uso de tecnología después de la pandemia.

VARIACIÓN EN USO DE TECNOLOGÍA POR ENTREVISTADO

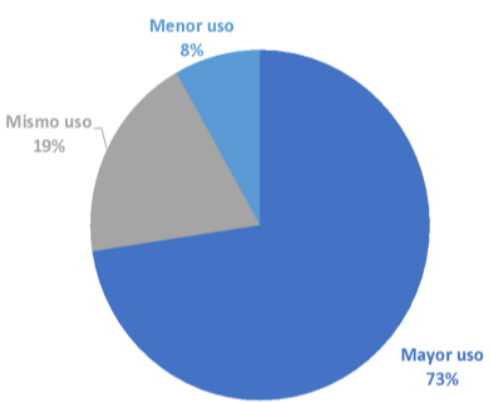

Nota. Desglose de variación en uso de las TIC, elaboración propia.

\section{¿En Cuáles Lugares Utilizaba Antes del Confinamiento sus Equipos y Con Qué Frecuencia?}

El 86.9\% de los entrevistados indicó da mayor uso a sus equipos en el hogar. Asimismo, el 61.0\% de los entrevistados indicó que la frecuencia de uso de sus equipos electrónicos es muchísimo, varias veces al día y el $26.8 \%$ indicó que dos o tres veces al día. Es importante observar que, de la población estudiada, la gran mayoría ya hacía uso de los equipos tecnológicos desde el hogar.

\section{Comunicación con Relacionados a Través de sus Dispositivos Electrónicos}

El 53.3\% de los entrevistados indicó que, con sus dispositivos electrónicos en este período de confinamiento, se relaciona principalmente con familiares; el 34.7\% indicó que con amigos y amigas; el $11.3 \%$ indicó que en el culto en la iglesia o templo. Respecto a la importancia que tiene para las PM el contacto con la familia y amigos para mantener una vida activa y saludable, los dispositivos electrónicos les están brindando esa posibilidad.

\section{Resultados del Registro Anecdótico}

Se presentan a continuación los datos del registro anecdótico que se recogieron con un grupo de 15 personas mayores de 60 años, que, en su gran mayoría, pertenecen al PAIPAM del Centro de Estudios Generales (CEG) de la Universidad Nacional de Costa Rica (UNA). Estas personas mayores, que en su mayoría son mujeres, asistían semanalmente a los cursos libres gratuitos del programa, donde se abordaban distintos temas de interés, desde la practicidad de las manualidades hasta las complejidades de los idiomas, todas las clases están orientadas a cumplir un mismo propósito y es el brindar un aprendizaje para la vida que les permita a las personas adultas mayores desarrollarse integralmente en estos espacios educativos, pues en ellos aprenden y socializan, lo que les genera un alto grado de satisfacción emocional que en muchas ocasiones no pueden lograr en sus hogares.

La realidad, para muchas de estas personas mayores, cambió en el momento en que se dio inicio al aislamiento social generado por la pandemia que Costa Rica ha tratado de controlar con rigurosas estrategias que hagan concientizar al pueblo sobre 
Sondeo de Casos en Personas Mayores sobre Actividades Cotidianas y Utilización de Tecnologías de la Información y la Comunicación (TIC) en Tiempos de Pandemia. el peligro al que se exponen ellos mismos y a sus seres queridos, empezando por sus mayores, esto si no cumplen a cabalidad las recomendaciones del Ministerio de Salud (MINSA). Después de dicha situación, muchas de las personas facilitadoras de los cursos, se dieron a la tarea de enviar materiales digitales como documentos, videos y fotografías asociados a los cursos que habían estado impartiendo, esto para mantener la relación con sus estudiantes, al menos a través de esta forma, lográndose mediante la aplicación de WhatsApp la cual sigue siendo una de las principales herramientas de comunicación para muchas de estas personas mayores.

Con el tiempo fueron surgiendo con gran auge las videoconferencias, reuniones virtuales, los webinarios, entre otros. Debido a esto, se generó la inquietud en algunas personas de la población estudiantil del PAIPAM sobre cómo participar de estos espacios y con ello surgió la pregunta sobre ¿cómo iniciar explicándole a alguien acerca del uso de la plataforma Zoom, si desconocían totalmente su existencia y uso? La respuesta estuvo en la actitud y el interés de cada una de las personas participantes, siendo los comentarios que se obtenían tales como "no sé cómo se usa eso, pero quiero aprender" o "todo es de sentarse y practicar", al tenerse expresiones tan favorables, lo siguiente para la persona capacitadora consistió en organizar su tiempo libre y armarse de paciencia para que la experiencia resultara agradable para todas las personas interesadas.

Sobre la disponibilidad de tiempo las personas que capacitan han tenido que extender mucho sus horarios ya que repetir las explicaciones y llamar a las líneas telefónicas es algo que se debe hacer con frecuencia. Este proceso de aprendizaje resulta fundamental, porque al menos por el momento la única posibilidad de mantenerse conectado y sobre todo las personas mayores, es a través del uso de las herramientas tecnológicas que se ofrecen en el mercado, mientras el escenario actual continúe.

Por otra parte, el grupo de personas adultas mayores del PAIPAM actualmente cuenta con su espacio de práctica, tertulia y diálogo sobre diversos tópicos, los cuales se llevan a cabo una vez a la semana durante dos horas. Los estudiantes que se sienten con mayor confianza respecto al dominio de Zoom han logrado incorporarse solos a diversas actividades a las que se les invita, lo cual les genera una notable sensación de bienestar que podría mencionarse como parte de los beneficios para su salud mental.

Estas actividades les permite salir de la rutina, aprender nuevos saberes, compartir con otras personas y externar sus opiniones que merecen ser escuchadas y atendidas. Esto es reforzado por la Organización Mundial de la Salud (2017) que establece que "a lo largo de la vida son muchos los factores sociales, psíquicos y biológicos que determinan la salud mental de las personas" (párr. 6); además agrega que "la salud mental influye en la salud del cuerpo, y a la inversa" (párr. 7). Esto quiere decir que una persona emocionalmente estable será lo suficientemente saludable para poder afrontar ciertas enfermedades físicas y/o neurodegenerativas que podrían repercutir en su diario vivir; de ahí la importancia de que las personas mayores puedan desarrollar sus relaciones interpersonales, y continuar con las capacitaciones de aprendizaje que antes desarrollaban, aunque sea de manera virtual y tener un espacio con sus grupos de contacto cercano.

Con respecto a los beneficios adicionales, se podría señalar que el uso de los dispositivos tecnológicos de telecomunicación han demostrado ser benéficos para la prevención del deterioro cognitivo asociado al Alzheimer y otras demencias, tal afirmación ha quedado plasmada a través de diversos estudios como lo informan Golimstok y Fernández (2020), del Servicio de Neurología del Hospital Italiano de Buenos Aires en Argentina, que en su conferencia titulada Cuando el smartphone hace bien afirmaron que "aquellas personas que saben utilizar un celular o que están activamente en contacto con las TIC, son las mismas que, incluso sin haberles realizado estudios o diagnósticos, ya se sabe que cuentan con más herramientas para defenderse ante una enfermedad" (párr. 4).

Todo esto no podrá sustituir jamás la interacción que originalmente se tenía, aunque logra rescatar parte de ella; sin embargo, lo más problemático de este panorama no se reduce a la forma de interactuar, sino al acceso a ella, pues algunas personas mayores quedan fuera, pues no todas cuentan con recursos para poder adquirir un celular inteligente que les permita acceder a WhatsApp o Zoom. También están quienes por el contrario se niegan rotundamente a sí mismos a tratar de romper la brecha tecnológica que los separa de poder conectarse para aprovechar los espacios a los que podrían tener acceso, algunas veces por temor y 
Sondeo de Casos en Personas Mayores sobre Actividades Cotidianas y Utilización de Tecnologías de la Información y la Comunicación (TIC) en Tiempos de Pandemia. otras porque simplemente no les inspira aprender el manejo de una herramienta tecnológica.

El simple hecho de ver reflejada una sonrisa de alegría en una persona mayor por haberse logrado conectar y estar participando en una reunión después de varios esfuerzos, resulta un motivador para reflexionar sobre la necesidad que tiene esta población tan importante en la sociedad, de ser tomada en cuenta y recuperar el rol de participación que ocupó en otros momentos de la historia.

\section{Discusión}

Los resultados obtenidos en este sondeo se agrupan a continuación a fin de visualizar los indicadores encontrados respecto a vida activa, uso de las TIC para actividades de comunicación, aprendizaje y recreación en PM que dieron origen a este estudio, siendo la muestra estudiada, un grupo no representativo del total de las personas mayores de las ciudades de la muestra de República Dominicana, Costa Rica y Argentina.

La población auscultada tiene edades entre 60 y 89 años, la mayoría (72\%) son de sexo femenino, más de la mitad tiene educación terciaria y un $17 \%$ primaria. Siendo el $82 \%$ residente en zona urbana y el resto rural. El $77 \%$ viven con familiares, y un 21 $\%$ viven solos. Un $53 \%$ están desarrollando actividades laborales remuneradas, 30\% no trabajan y $17 \%$ están pensionados, casi la totalidad hace uso de las TIC.

Es interesante observar que, si bien un poco más de la mitad de las personas entrevistadas desarrollan trabajos remunerados, en igual porcentaje se vieron afectados en sus ingresos a partir de la pandemia en virtud de que no fue posible desarrollar las actividades como lo hacían anteriormente y este impacto es algo a tomar en consideración, dado que esta es la población más vulnerable $\mathrm{y}$, por ende, la que debería tener a resguardo sistemas de protección ante los nuevos escenarios.

Respecto a las actividades cotidianas del día a día, se pudo comprobar que la mayoría de las personas de la muestra, aunque a veces no sienten deseos, se mantienen realizando actividades en el hogar, entretenimiento, aprendizajes y otras. Tanto la OMS como en la Enciclopedia de la salud hacen referencia a que una vejez saludable es más posible si la persona mantiene buenas relaciones interpersonales, actividades físicas y actividades intelectuales como leer, aprender algo nuevo, desarrollar actividades artísticas como pintar, entre otros.

En los casos que participaron en el sondeo, cabe señalar que un $75 \%$ realizan actividades por las mañanas y por la tarde y noche lo hace casi el 100 por ciento. Siendo más frecuente que las tareas del hogar se desarrollen entre la mañana y la tarde, y las actividades vinculadas con el entretenimiento en la tarde y por la noche.

Respecto a las actividades de aprendizaje, que es un aspecto puntual de interés en este estudio, se pudo observar que un $15 \%$ de las actividades de la mañana y en igual porcentaje por las tardes se agrupan en actividades de aprendizaje y básicamente consisten en leer libros o buscar información, aprender un idioma, ver videos instructivos y escribir documentos. Respecto a esta última categoría cabe señalar que más de la mitad de las personas de la muestra desarrollan trabajos y pueden ser documentos de trabajo, aunque no se recuperó ese dato.

En relación con los dispositivos utilizados para actividades de aprendizaje, un $41 \%$ usa para ello la PC (computadora); un 35\% emplea la tableta y el celular es utilizado en este tipo de actividades en un $36 \%$. Vale decir que los tres tipos de dispositivos son utilizados para aprender.

Las actividades relacionadas con aprendizajes resultan un indicador importante del envejecimiento activo y el estado emocional, ya que, para aprender nuevos conocimientos, es necesaria una decisión en la que interviene no solo la esfera cognitiva, sino que permea otras capas fundamentales como la emocional y la anímica que durante el proceso se ven comprometidas de diversas formas $y$ mantienen activa la mente, el entusiasmo, los propósitos, entre otros.

Es necesario resaltar lo mencionado respecto al esfuerzo de adaptación a las nuevas tecnologías educativas, a través de herramientas virtuales, lo que representa un desafío insoslayable para poder mantener cursos y actividades de aprendizaje que antes de la pandemia se hacían en forma presencial. En este grupo muestral no se percibe que la adaptación a las TIC haya resultado traumática ni que tuvieran limitaciones para continuar con las actividades de aprendizaje que realizaban antes debido a que podían hacerlo de manera virtual. 
Sondeo de Casos en Personas Mayores sobre Actividades Cotidianas y Utilización de Tecnologías de la Información y la Comunicación (TIC) en Tiempos de Pandemia.
Por su parte, el reto del uso de las TIC representa una barrera para muchas personas mayores, aunque en este trabajo por las características de la población encuestada no se visualice, ya que no se tuvo acceso a poblaciones de escasos recursos donde la brecha con la tecnología es aún un obstáculo para vencer. Sunkel y Ullmann (2019), estiman que la población de personas adultas mayores que accede a Internet es bien limitada, estimada entre 7 y 9 veces menor a la población entre 15-29 años en diferentes países de la región.

La situación generada por la COVID-19 ha impactado emocionalmente a la población estudiada en un $60 \%$ de los casos generando preocupación, miedo, incertidumbre, malhumor y estrés, si a esto le sumamos la merma en sus ingresos, resulta un panorama que poco favorece a esta población.

Esta población en particular tal como se evidenció necesita de manera primordial estar vinculada a sus familiares y amigos, siendo el principal indicador que se menciona en los estudios de calidad de vida de las personas mayores y de envejecimiento activo lo cual "contribuye un montón para mantener la salud física y psíquica de las personas adultas mayores..." (Muñiz, 2018, párr. 5 y $3)$.

Por ello, la posibilidad de acceso a las TIC vino a tender un puente vital en este momento de confinamiento porque la población objeto de estudio es la que con mayor cuidado debe estar aislada y en esta muestra ha resultado significativo el vínculo que han podido mantener las personas mayores con sus seres queridos, aunque se hacía referencia en algunos casos a la falta de cercanía como un problema, se resalta la posibilidad de estar conectados gracias al celular, la PC y la tableta. Un 73\% reconoció que ha hecho mayor uso de las TIC a partir del confinamiento, fundamentalmente para comunicarse con familiares, amigos y actividades de culto a través del chat, llamadas y el uso de las redes sociales.

\section{Conclusiones}

En resumen, este grupo de personas mayores que colaboró para la realización del sondeo, hasta el momento del levantamiento de los datos se mantenían activas, aunque con variables niveles de estrés, la mayoría realizan diversas actividades que varían entre quehaceres del hogar, aprendizaje y entretenimiento; además mantienen una fluida comunicación con la familia, amigos y actividades de culto.

Esta posibilidad de acceso a las TIC es la oportunidad de comunicación y aprendizaje que de otra manera no hubiera sido posible, y es por ello que se puede predecir que hay una alta probabilidad de que las PM de la muestra puedan continuar con un envejecimiento saludable, ya que es indispensable para ello, estar activos y mantener muy buena comunicación con familia y amigos, lo cual se comprobó en este grupo. Así también, por los resultados de este estudio se estima que en general las PM que tengan acceso a las TIC tendrán mayores posibilidades de mejorar su calidad de vida.

Los resultados arrojados en este grupo permiten inferir información sobre la utilización de las TIC, sin embargo, lo deseable sería desarrollar líneas de investigación para observar el comportamiento de las mismas variables en una muestra representativa de la población adulta mayor en zonas rurales, diferentes niveles socioeconómicos, educativos y otros espacios como hogares de día y asilos.

Así también sería conveniente brindar espacios de capacitación tecnológica para personas mayores involucrando a líderes naturales de la comunidad que creen redes de trabajo social, así como a familiares de dicha población, lo cual reforzará las relaciones intergeneracionales e interpersonales. Es importante que estas propuestas estén acompañadas de políticas públicas para mejorar el acceso asequible a Internet, que se realicen donaciones de equipos y que se creen contenidos o servicios públicos digitales dirigidos a este grupo poblacional.

\section{Referencias}

Almeyda, J. F., Chez, C. y Larancuent, O. (2018). Comprendiendo los retos al desarrollo del e-commerce en la República Dominicana. Cámara Americana de Comercio de la República Dominicana. https://www.amcham.org.do/images/pdf/WhitepaperFinal-compressed.pdf

Arias, C. J. y Polizzi, L. (2011). La amistad en la vejez. Funciones de apoyo y atributos del vínculo [ponencia]. III Congreso Internacional de Investigación y Práctica Profesional en Psicología XVIII Jornadas de Investigación Séptimo Encuentro de Investigadores en Psicología del MERCOSUR, Facultad de Psicología de la Universidad de Buenos Aires, Argentina. Recuperado de: https://www.aacademica.org/000-052/350 
Sondeo de Casos en Personas Mayores sobre Actividades Cotidianas y Utilización de Tecnologías de la Información y la Comunicación (TIC) en Tiempos de Pandemia.
Cardozo, C., Martín, A. E., y Saldaño, V. (2017). Los adultos mayores y las redes sociales: Analizando experiencias para mejorar la interacción. Informes Científicos Técnicos de la Universidad Nacional de la Patagonia Austral, 9(2), 1-29. https://doi.org/10.22305/ict-unpa.v9i2.244

García, S. (2010). Envejecimiento activo y saludable. Revista ;Hola! Recuperado de: https://www.hola.com/salud/enciclopediasalud/2010062045408/mayores/generales/envejecimientoactivo-y-saludable

Golimstok, A. y Fernández, M. (2020). Cuando el smartphone hace bien. Hospital Italiano de Buenos Aires. https://www.hospitalitaliano.org.ar/\#!/home/aprender/noticia/93 442

López, D. F. (2007). La naturaleza de las tecnologías de información y comunicación: las TIC como determinantes de la organización y de la sociedad de la información. Palabra Clave, 10(1), 72-93. Recuperado http://dspace.uhemisferios.edu.ec:8080/xmlui/handle/123456789 1453

Ministerio de Salud de Argentina. (2020). Reporte diario matutino nro 89 Situación de COVID-19 en Argentina. https://www.argentina.gob.ar/sites/default/files/28-0420_reporte-matutino-covid-19.pdf

Ministerio de Salud de Costa Rica. (2020). 705 casos confirmados por COVID-19. Recuperado de: https://www.ministeriodesalud.go.cr/index.php/centro-deprensa/noticias/741-noticias-2020/1637-705-casos-confirmadospor-covid-19

Molina, C. J. y Meléndez, J. C. (2006). Bienestar psicológico en envejecientes de la República Dominicana. Geriátrika: Revista Iberoamericana de Geriatría y Gerontología, 22(3), 25-33. https://www.uv.es/melendez/envejecimiento/bienestar.pdf

Mujica, R. (2019). La tecnología en la educación. Revista Tecnológica$\begin{array}{llll}\text { Educativa Docentes } & 2.0, & 4(4), & 4-7 .\end{array}$ https://ojs.docentes20.com/index.php/revistadocentes20/article/view/57

Mujica, R. (2019). Sociedad del conocimiento. Revista Tecnológica$\begin{array}{llll}\text { Educativa Docentes 2.0, 6(4), 9-11. } & \text {. }\end{array}$ https://doi.org/10.37843/rted.v6i4.75

Muñiz, N. (2018). La amistad mejora la calidad de vida en la vejez. Diario Popular. https://www.diariopopular.com.ar/general/laamistad-mejora-la-calidad-vida-la-vejez-n359505

Organización Mundial de la Salud. (2015). Informe mundial sobre el envejecimiento y la salud. Recuperado de: https://www.who.int/ageing/publications/world-report-2015/es/

Organización Mundial de la Salud. (2017, 12 de diciembre). La salud mental $y$ los adultos mayores. Recuperado de: https://www.who.int/es/news-room/fact-sheets/detail/la-saludmental-y-los-adultos-mayores

Parra-Rizo, M. A. (2017). Componentes de influencia más valorados en la calidad de vida por las personas mayores de 60 años físicamente activas. European Journal of Investigation in Health, Psychology and Education, 7(3), 135-144. https://doi.org/10.30552/ejihpe.v7i3.202
Peguero, A. (2020). Ascienden a 286 los fallecidos por COVID-19 y a 6,416 los infectados en República Dominicana. Diario Libre. Recuperado de: https://www.diariolibre.com/actualidad/salud/ascienden-a-286los-fallecidos-por-covid-19-y-a-6416-los-infectados-enrepublica-dominicana-GM18505535

Prensky, M. (2001, 1 de septiembre). Digital natives, digital immigrants Part 1. On the Horizon, 9(5), 1-6. https://doi.org/10.1108/10748120110424816

Prieto, D., Etxeberría, I., Galdona, N., Urdaneta, E., Yanguas, J. y los miembros de la Fundación Ingema. (2009). Las dimensiones subjetivas del envejecimiento. Instituto de Mayores y Servicios Sociales. Recuperado de: https://www.imserso.es/imserso_01/documentacion/publicacion es/colecciones/informacion_publicacion/index.htm?id=2

Sandoval, E. (2018). Tercera edad y la importancia de las relaciones interpersonales. Instituto de Políticas Públicas en Salud. Recuperado de: http://www.ipsuss.cl/ipsuss/columnas-deopinion/eduardo-sandoval/tercera-edad-y-la-importancia-delas-relaciones-interpersonales/2018-03-06/172633.html

Selwyn, N. (2003). Apart from technology: understanding people's non-use of information and communication technologies in everyday life. Technology in Society, 25(1), 99-116. https://doi.org/10.1016/S0160-791X(02)00062-3

Sevilla, M., Salgado, M. C. y Osuna, N. C. (2015, 3 de agosto). Envejecimiento activo. Las TIC en la vida del adulto mayor. Revista Iberoamericana para la Investigación y el Desarrollo Educativo, 6(11), 574 - $587 . \quad$ Recuperado de: https://www.ride.org.mx/index.php/RIDE/article/view/138

Sunkel, G. y Ullmann, H. (2019). Las personas mayores de América Latina en la era digital: superación de la brecha digital. Comisión Económica para América Latina y el Caribe, (127), 243-268. Recuperado de: http://hdl.handle.net/11362/44569

Tello-Rodríguez, T., Alarcón, R. D. y Vizcarra-Escobar, D. (2016). Salud mental en el adulto mayor: Trastornos neurocognitivos mayores, afectivos y del sueño. Revista Peruana de Medicina Experimental y Salud Pública, 33(2), 342-350. https://doi.org/10.17843/rpmesp.2016.332.2211

Verity, R., Okell, L. C., Dorigatti, I., Winskill, P., Whittaker, C., ... Ferguson, N. M. (2020). Estimates of the severity of coronavirus disease 2019: a model-based analysis. The Lancet Infectious Diseases, 20, 669-77. https://doi.org/10.1016/S14733099(20)30243-7 
Sondeo de Casos en Personas Mayores sobre Actividades Cotidianas y Utilización de Tecnologías de la Información y la Comunicación (TIC) en Tiempos de Pandemia.

\section{Apéndice}

\section{Encuesta bienestar adultos mayores}

Gracias por colaborar con sus respuestas para este trabajo.

Nuestro interés es recoger información que nos permita conocer algunas características de cómo están viviendo las personas mayores de 65 años durante el tiempo de esta pandemia, a fin de que puedan tomarse medidas de mejora, cuando sea posible.

No hay respuestas correctas o incorrectas, sólo nos interesa su opinión tal cual como Ud. lo vive o piensa.

Las respuestas que nos brinde son totalmente anónimas, no necesitamos su nombre, sólo su

(a)

Muchas gracias

\section{Cuéntenos sobre usted...}

... los datos siguientes

1.Edad

\section{Sexo}

Marca solo un óvalo.
Mujer
Hombre
Otro:

3. Nivel educativo

Marca solo un óvalo.

Primaria

Secundaria

Técnico-profesional

Universitario

No fui a la escuela

Otro:

\section{Lugar de residencia}

Marca solo un óvalo.

Rural

Urbano

5. ¿Con quién vive?

Marca solo un óvalo.

Solo(a)

Con familiares

Hogar de día (centro diurno)

Centro de acogida para adultos mayores

Otro:

6. ¿Trabaja o desempeña alguna actividad remunerada?

Marca solo un óvalo.

$\bigcirc \mathrm{si}$

Soy pensionado o pensionada

Otro:
II. En los últimos meses...

favor responder a las siguientes preguntas

8. 8 ¿Ha visto afectada su actividad productiva?

Marca solo un óvalo.

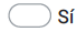

$\bigcirc$ No

Otro:

9. En caso de responder afirmativamente la pregunta anterior, favor describir

III. Hablemos de su dia normal..

$\mathrm{y}$ las actividades que realiza

10. ¿Cómo se ha sentido animicamente? Favor describir

Selecciona todos los que correspondan.

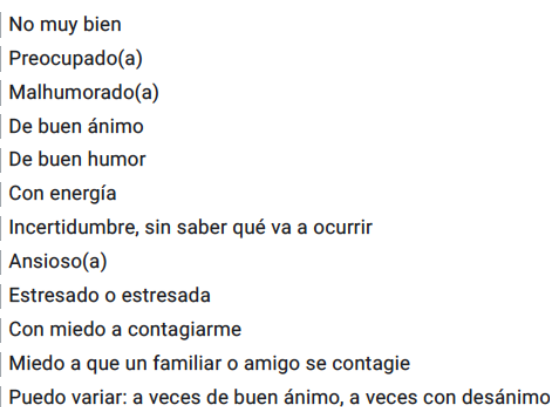

12. En la tarde, desde el almuerzo, favor enumere ¿cuáles tareas o actividades realiza?

Selecciona todos los que correspondan.

Descansar o tomar la siesta
Preparar café
Tomar café
Hablar por teléfono
Bañarse
Estudiar
Leer noticias
Regar plantas
Leer la biblia
Orar
Quehaceres domésticos
Salir a negocio
Salir a trabajar
Salir a diligencias
Ver televisión
Leer libro

14. Dentro de las actividades que están permitidas, ¿hay alguna/s que le gustaria hacer y no ha podido?

Marca solo un óvalo.

$\square^{\mathrm{Ni}}$


Sondeo de Casos en Personas Mayores sobre Actividades Cotidianas y Utilización de Tecnologías de la Información y la Comunicación (TIC) en Tiempos de Pandemia.

15. En caso de responder afirmativamente la pregunta anterior, favor describir

16. Favor indicar si tiene alguna debilidad o discapacidad que le impida hacer uso de alguna tecnologia entre las siguientes (puede marcar varias):

Selecciona todos los que correspondan.

Visual

Auditiva

De movilidad física

Cognitiva

Ninguna

Otro:

IV. Sobre el uso que hace de las tecnologias de la información

... y comunicaciones por usted

17. ¿Tiene acceso a internet?

Marca solo un óvalo.

$C_{\text {Sí }}$

$C_{\text {No }}$

No sabe

18. En caso de tener acceso, ¿quién paga el servicio de internet?

Marca solo un óvalo.
Yo misma
Mi familia
Otro:

19. ¿Cuáles tipos de dispositivos, aparatos o equipos sabe utilizar?

Selecciona todos los que correspondan.

Computador personal o de escritorio (PC)

Tableta (iPad o Tablet)

Celular (Smartphone, iphone u otro)

No sé utilizarlos

Otro:

20. ¿Tiene computador personal, laptop o PC?

Marca solo un óvalo.

SI

No
21. En caso de tener acceso a una computadora personal o de escritorio, favor enumere para cuáles tareas o actividades la utiliza

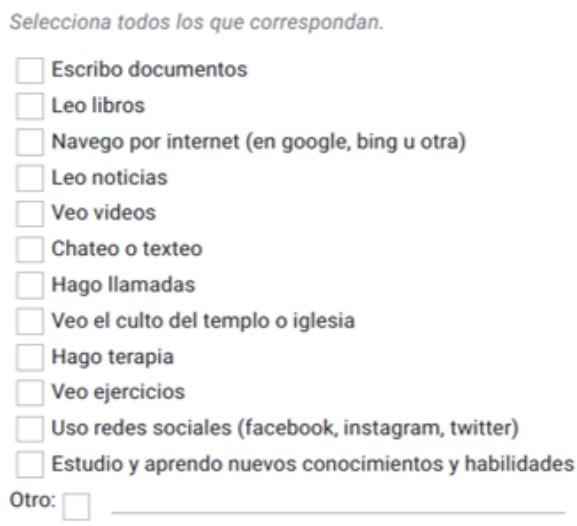

22. ¿Tiene tableta, iPad o Tablet?

Marca solo un óvalo.

$\mathrm{Si}$

No

24. ¿Tiene celular, iPhone, Samsung o cualquier marca?

Marca solo un óvalo.

Si

No

26. ¿Cuáles de las siguientes herramientas informáticas utiliza con mayor frecuencia?

\section{Selecciona todos los que correspondan.}

Buscadores tales como Google o Bing

Correo Electrónico tales como Gmail, Hotmail u otro

Chateo (tales como Whatsapp, SMS, Telegram, Messenger)

Redes sociales (tales como Facebook, Twitter, Instagram)

Periódicos digitales (tales como Listín diario, Diario Libre, Hoy)

Youtube (para ver documentales, videos o aprender)

Teléfono con video (tales como zoom, skype, facetime, meet)

Otro:

27. A partir del periodo de distanciamiento social a causa de la pandemia... ¿qué tanto ha variado el uso de sus equipos o dispositivos?

Marca solo un óvalo

Menor uso

Mismo uso

Mayor uso

28. ¿En cuáles lugares utiliza sus dispositivos o equipos?

Selecciona todos los que correspondan.

Hogar

Asilo

Centros especializados de asistencia

Otro: 
Sondeo de Casos en Personas Mayores sobre Actividades Cotidianas y Utilización de Tecnologías de la Información y la Comunicación (TIC) en Tiempos de

29. De las siguientes, ¿cuál describe la frecuencia en que utiliza los dispositivos?

Marca solo un óvalo.

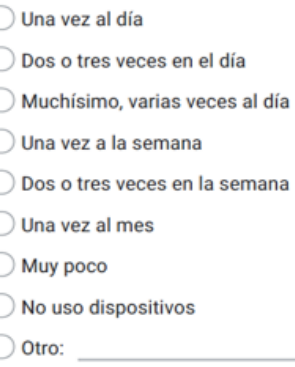

32. ¿Cómo describiria de qué manera se siente con el contacto que tiene actualmente con sus allegados?

\section{A través de cuáles otros medios se comunica con sus familiares}

Selecciona todos los que correspondan.

Por teléfono

Por cartas

Visitas

Otro:

34. Hemos concluido la entrevista, ¿le gustaria colaborar con algún comentario adicional, en adición a lo que nos ha respondido?

Agradecemos su colaboración porque sus respuestas serán de gran utilidad para intentar incidir en la toma de conciencia sobre las necesidades de las personas mayores en este periodo de distanciamiento social Muchas gracias. 